Encrucijada/Crossroads: An Online Academic Journal

Issue 1, Volume 12003

\title{
English or Spanish: Making Linguistic Decisions in the United States
}

\author{
Edwin Lamboy \\ Language Program Coordinator for Spanish and Italian \\ Montclair State University
}

\section{Introduction}

Historically, Hispanics have had to face and deal with a linguistic controversy upon arrival to the U.S., that of living in a society whose dominant language is not Spanish. The resulting dichotomy has had and continues to have interesting repercussions for Hispanics and their descendants in this country. Spanish has had to compete with English, and as Alejandro Portes and Richard Schauffler explain, certain trends have been established:

In the past, the typical pattern has been for the first generation to learn enough English to survive economically; the second generation continued to speak the parental tongue at home, but English in school, at work and in public life; by the third generation, the home language shifted to English, which effectively became the mother tongue for subsequent generations. (643)

Despite this, the retention rates of Spanish are high, especially when they are compared to other immigrant languages. There has been an uninterrupted transmission of Spanish from generation to generation across decades and "Hispanics show a high degree of Spanish maintenance even among the nativeborn" (Bean and Tienda 259).

According to Yolanda Russinovich Solé, Cuban-Americans have the highest retention rate (75.5 percent), followed by Puerto Ricans (66.7 percent), Mexican-Americans (64.6 percent), and the 'Other-Spanish' sub-group (60.4 percent) (39). Each group shows more Spanish maintenance in those areas where its members are the most represented. Thus, Cuban-Americans have higher degrees of maintenance in Florida, Puerto Ricans in New York, and MexicanAmericans and Chicanos in the Southwest (39-40).

In most cases, however, the solution to the aforementioned linguistic controversy has been a movement toward bilingualism. The acquisition and use of the Spanish and English linguistic codes remains as "the dominant pattern of accommodation to the American environment" (Solé 38). Bilingualism among 
Hispanics, nevertheless, is restricted by levels of English and Spanish fluency. As Carmen Silva-Corvalán says, "Spanish illustrates a continuum of levels of proficiency along which speakers move, up or down, either in their lifetime or across generations (there is also a clear proficiency continuum in English)" (Language Contact 220-21). Moreover, speakers show a great deal of variation based on sociolinguistic factors such as gender, economic status, occupational categories, age, and context of interaction.

The New York City metropolitan area has been one of the preferred host enclaves for Latino immigrants, including Puerto Ricans, Dominicans, and Cubans. Puerto Ricans are the most represented. Their migration to this city peaked between 1945 and 1965 due to the deploring economic situation of the island as opposed to the increasingly fruitful economy of the mainland. Thus, many of the members of this community are second generation speakers of Spanish. The out-migration of Dominicans to the U. S., on the other hand, was motivated by political reasons, that is, the dictatorship of General Trujillo. In 1961, when the general was assassinated, the U.S. consulate facilitated the acquisition of visas in order to avoid the development of a political system like that of Cuba. In the late ' 70 s and ' 80 s, the Dominican population in the U. S. increased dramatically. Finally, Cubans arrived at this area primarily for political reasons. Most of them arrived in the early 1980s and they are known as the Marielitos. This new influx dramatically altered the composition of the Cuban population in the New York City metropolitan area, which had consisted mostly of well-educated individuals with promising economic futures who had come soon after Castro's rise to power. Table 1 reveals the impact of the immigration of these three groups as presented in the Census of Population and Housing: Census Tracts and BNA's (New York).

Table 1. Number of Cubans, Dominicans, and Puerto Ricans living in New York City according to the 1990 census

\begin{tabular}{|l|c|c|c|}
\hline Ethnic origin & $\mathrm{n}$ & $\begin{array}{c}\% \text { among Hispanics } \\
(\mathrm{n}=1,889,662)^{*}\end{array}$ & $\begin{array}{c}\text { \% of entire population } \\
(\mathrm{n}=8,546,846)^{*}\end{array}$ \\
\hline Cubans & 61,989 & 3 & 1 \\
\hline Dominicans & 342,553 & 18 & 11 \\
\hline Puerto Ricans & 933,329 & 49 & 6 \\
\hline Other Hispanics & 551,791 & 29 & 4 \\
* Percentages are rounded up.
\end{tabular}

This paper reports the results of a study that considers some of the linguistic decisions that first-generation (hereafter FG) and second-generation (hereafter SG) Cubans (hereafter C), Dominicans (hereafter D), and Puerto Ricans (hereafter PR) make in the New York City area, as

Encrucijada/Crossroads 1.1 (2003): 33-46 
well as some factors that may possibly determine these decisions. The importance of this approach lies on the need to understand the forces responsible for the manifestations of the bilingualism that characterizes Latinos in this country. The results may have implications in other fields such as education and sociology, and may help uncover some of the measures necessary to ensure further Spanish language maintenance. These are based on the answers provided by 58 Latinos living in the New York City metropolitan area. Table 2 classifies the subjects according to generation, sex, age group, and ethnic group.

Table 2. Number of subjects according to generation, sex, age group, and ethnic group

\begin{tabular}{|c|c|c|c|c|c|c|c|c|c|c|c|c|c|}
\hline Generation & \multicolumn{6}{|c|}{ First } & \multicolumn{6}{|c|}{ Second } & \\
\hline Sex & \multicolumn{3}{|c|}{$\mathrm{M}$} & \multicolumn{3}{|c|}{$\mathrm{F}$} & \multicolumn{3}{|c|}{$\mathrm{M}$} & \multicolumn{3}{|c|}{$\mathrm{F}$} & \\
\hline Age Group & 1 & 2 & 3 & 1 & 2 & 3 & 1 & 2 & 3 & 1 & 2 & 3 & \\
\hline \multicolumn{13}{|l|}{ Ethnic Group } & Totals \\
\hline Cubans & 2 & 2 & 1 & 2 & 2 & 1 & 2 & 2 & 0 & 2 & 1 & 1 & $=18$ \\
\hline Dominicans & 1 & 2 & 1 & 2 & 2 & 2 & 2 & 2 & 1 & 1 & 2 & 2 & $=20$ \\
\hline Puerto Ricans & 2 & 1 & 2 & 1 & 3 & 1 & 1 & 3 & 1 & 2 & 2 & 1 & $=20$ \\
\hline & & & & & & & & & & & & & $\mathrm{n}=58$ \\
\hline
\end{tabular}

M=Males: F=Females; Age Groups: $1=20-35 ; 2=36-50 ; 3=51$ and over

The utilized model included thirteen dependent variables that involve a certain degree of decision-making. These variables were grouped in three different thematic clusters, namely:

1) Language(s) of the home

a) Language(s) of the home at age 13

b) Language(s) of the home now

2) Exposure to means of communication

a) Spanish-language radio and music

b) English-language radio and music

c) Spanish-language television

d) English-language television

e) Spanish-language newspapers and magazines

f) English-language newspapers and magazines

3) Domains

a) Language(s) used in the job environment

b) Language(s) used with family members

c) Language(s) used with close friends

d) Language(s) used with other members of the same ethnic group

e) Language(s) used with other Latinos 
Analyses of variance were performed considering generation; sex; generation and sex; and generation and ethnic group as independent variables, and the eleven dependent variables in the categories of exposure to means of communication and domains.

\section{The Study}

Data collection consisted of two phases. The first phase involved the selection of subjects. Most of them were identified and chosen in those areas where their specific ethnic groups are highly concentrated $-\mathrm{C}$ in Hudson County, $\mathrm{NJ}$; D in Washington Heights, NY; and PR in El Barrio, NY. ${ }^{1}$ I was first introduced to these individuals by members of the communities and people who provide services in these communities. Afterwards, some of the subjects provided me with names of other prospective candidates for the study. All of the subjects were twenty years old or over. The study was controlled for age and gender in order to obtain a representative sample.

Phase two involved a questionnaire. It included questions dealing with demographic information and other questions that were not considered in this study. ${ }^{2}$ The questions dealing with language(s) of the home and domains provided a five-point scale in which $1=$ Spanish only, $2=$ mostly Spanish, $3=$ both Spanish and English, 4 = mostly English, and 5 = English only.

The questionnaire asked subjects to indicate the average of hours per week they exposed themselves to Spanish- and English-language radio and music; and Spanish- and English-language television. ${ }^{3}$ Finally, the questions dealing with frequency with which the subjects read Spanish- and English-language newspapers and magazines provided a seven-point scale in which $1=$ daily, $2=$ several times a week, $3=$ once a week, $4=$ about once a month, $5=$ several times a month, $6=$ less than once a month, and $7=$ never. The questionnaire was available in both Spanish and English, and the subjects were asked to choose.

The means of the values indicated by the subjects were calculated and four analyses of variance were conducted using generation; sex; generation and sex; and generation and ethnic group as independent variables.

\section{The Results}

Table 3 presents a comparison of the language(s) of the home on the $13^{\text {th }}$ birthday and the language(s) of the home now for the subjects from the three ethnic groups. The averages presented in the table represent the language choice or the average of points on the scale. Among the FG members, D had the lowest average for language(s) of the home at age 13 (1, "Spanish only") and for language(s) of the home now (2, "mostly Spanish"). PR had the highest average for the first category (1.3, between "Spanish only" and "mostly Spanish"). C had

Encrucijada/Crossroads 1.1 (2003): 33-46 
the highest average for the second category (2.6, between "mostly Spanish," and "both Spanish and English"). There are no great differences between the averages for these categories.

TABLE 3. Comparison of first- and second-generation Cubans,

Dominicans, and Puerto Ricans based on the language(s) spoken at home on their $13^{\text {th }}$ birthday and the language(s) spoken at home now

\begin{tabular}{|c|c|c|c|c|c|c|c|c|c|c|}
\hline & & & & & & & & Differ & nce & \\
\hline Gene & & & First & & & Second & & & & \\
\hline Ethn & roup & $\mathrm{C}$ & DR & PR & $\mathrm{C}$ & DR & PR & $\mathrm{C}$ & DR & PR \\
\hline & & LH13 & & & LH13* & & & LH13 & & \\
\hline $\mathrm{AG}$ & 1 & 1.3 & 1 & 1 & 1.8 & 1 & 3 & +.5 & 0 & +2 \\
\hline & 2 & 1 & 1 & 1.5 & 1.7 & 1 & 2.6 & +.7 & 0 & +1.1 \\
\hline & 3 & 1 & 1.5 & 1.3 & 4 & 1.3 & 4 & +2.5 & +.3 & +2.7 \\
\hline $\mathrm{TG}$ & & 1.2 & 1 & 1.3 & 2 & 1.1 & 3 & +.8 & +.1 & +1.7 \\
\hline & & LHN* & & & LHN* & & & LHN* & & \\
\hline $\mathrm{AG}$ & 1 & 2.8 & 1.7 & 2.7 & 3.5 & 2 & 3.3 & +.7 & +.3 & +.6 \\
\hline & 2 & 2.3 & 2 & 2.8 & 3 & 3 & 3.2 & +.7 & +1 & +.4 \\
\hline & 3 & 3 & 2.3 & 1.7 & 5 & 3 & 4 & +2 & +.7 & +2.3 \\
\hline TG & & 2.6 & 2 & 2.4 & 3.5 & 3.7 & 3.4 & +.9 & +.7 & +1 \\
\hline Diffe & ce (L & $-\mathrm{LH} 1$ & & & & & & & & \\
\hline $\mathrm{AG}$ & 1 & +1.5 & +.7 & +1.7 & +1.7 & +1 & +.3 & & & \\
\hline & 2 & +1.3 & +1 & +1.3 & +1.3 & +2 & +.6 & & & \\
\hline & 3 & +1.5 & +1.3 & +.4 & +1 & +1.7 & 0 & & & \\
\hline TG & & +1.4 & +1 & +1.1 & +1.5 & +1.6 & +.4 & & & \\
\hline $\begin{array}{l}*^{*} \text { Resl } \\
1=S_{t} \\
5=E \\
C=C \\
L H 13 \\
A G= \\
T G=\end{array}$ & $\begin{array}{l}\text { giver } \\
\text { ish or } \\
\text { sh on } \\
\text { ins; L } \\
\text { angl } \\
\text { e gro } \\
\text { al gr }\end{array}$ & $\begin{array}{l}\text { avera } \\
2=M o \\
\text { Domin } \\
\text { of the } \\
=20\end{array}$ & $\begin{array}{l}\text { es of po } \\
\text { ty Spa } \\
\text { ans; } P \\
\text { ome on } \\
5 ; 2=\end{array}$ & $\begin{array}{l}\text { its on } \\
\text { sh; } 3 \\
=P u \\
\text { he } 13^{t}\end{array}$ & $\begin{array}{l}\text { the foll } \\
=\text { Both } \\
\text { rto Rice } \\
\text { birthd } \\
=51\end{array}$ & $\begin{array}{l}\text { ing sce } \\
\text { anish } \\
\text { : LHN } \\
\text { d over }\end{array}$ & $E n$ & se of $t$ & hon & now \\
\hline
\end{tabular}

D also had the lowest averages for these categories among their SG members: 1.1 (between "Spanish only" and "mostly Spanish") and 2.7 (between "mostly Spanish," and "both Spanish and English"), respectively. PR had the highest average for the first category (3, "both Spanish and English"), and C had the highest for the second one (3.5, between "both Spanish and English," and "mostly English"). Again, there are no great differences between the averages for these categories.

One can confirm that the tendency is for an individual-from the FG or the $\mathrm{SG}-$ to use more English now than when he or she was 13 years old, as the movement on the scale shows. (See bottom section of the table.) All the ethnic groups and generations showed an increase except for the SG PR from age group 3 . The data suggests that these individuals are providing for their children a home 
environment in which English is used more than when they were 13 years old, and this is destined to increase when they have children of their own. Table 4 illustrates how many hours per week the subjects are exposed to Spanish- and English-language radio and music. The numbers presented are averages of hours per week that the particular group spends listening to Spanish- and Englishlanguage radio and music. In the FG group, $\mathrm{C}$ had the highest average of hours per week for listening to Spanish-language radio and music (23.6 hours). D had the lowest, with 2.6 hours. PR had the highest average for listening to Englishlanguage radio and music, with 8.8 hours. D had the lowest, with 6.7 hours.

Among the SG members, D listen to Spanish-language radio and music more than the other groups (15.6 hours), while PR listen to it less than the other groups (8.8 hours). PR, however, listen to English-language radio and music more than the other groups (20.1 hours). C listen to it less than the other two groups (17.6 hours).

Table 4. Comparison of first- and second-generation Cubans, Dominicans, and Puerto Ricans based on their exposure to Spanish- and English-language radio and music

\begin{tabular}{|l|l|c|c|c|c|c|c|c|c|c|}
\hline \multicolumn{9}{|c|}{ First } & \multicolumn{3}{l|}{ Second } & \multicolumn{3}{l|}{} \\
\hline Generation & \multicolumn{3}{|c|}{ Difference } \\
\hline Ethnic group & C & DR & PR & C & DR & PR & C & DR & PR \\
\hline \multicolumn{3}{|l|}{ SRM } \\
\hline
\end{tabular}

* Results are given in average of hours per week. $C=$ Cubans; $D=$ Dominicans; $P R=$ Puerto Ricans

$S R M=$ Spanish radio and music; $E R M=$ English radio and music

$A G=$ Age group: $1=20-35 ; 2=36-50 ; 3=51$ and over

$T G=$ Total group

The average of hours per week listening to Spanish-language radio and music decreases in the SG whereas the average of hours listening to Englishlanguage radio and music increases. These differences are statistically significant for generation, but only in the case of English-language radio and music. Exposure to Spanish-language radio and music, on the other hand, correlates with generation and ethnic group $(\mathrm{p}<.0163)$. This is attributable to the relatively low frequency with which FG D listen to radio and music in Spanish, and to the 
relatively high frequency with which FG $\mathrm{C}$ do it. The other four subgroups yielded very similar means. Finally, sex did not correlate with any of these dependent variables.

Let us consider how many hours per week the subjects are exposed to Spanish- and English-language television. The results are included in Table 5. The numbers included in the table are averages of hours per week. $\mathrm{C}$ watch more Spanish-language television than any other FG group (22.9 hours per week). D watch the least, with 9.8 hours per week. PR watch 19.2 hours of Englishlanguage television, more than any other group. D watch 10.3 hours, less than any other group. Among the SG, D watch more Spanish-language television, with 10.5 hours. C watch the least, 3.4 hours. PR, on the other hand, watch more English-language television, 25.8 hours per week. $\mathrm{C}$ watch 17.6 hours, being the group that watches the least. The generational factor yielded significant statistical results for both Spanish-language $(\mathrm{p}<.0106)$ and English-language television $(\mathrm{p}<.0001)$. Sex; and generation and ethnic group did not.

Table 5. Comparison of first- and second-generation

Cubans, Dominicans, and Puerto Ricans based on their exposure to Spanish- and English-language television

\begin{tabular}{|c|c|c|c|c|c|c|c|c|c|c|}
\hline & & & & & & & & Differ & & \\
\hline Gen & ion & & First & & & econc & & & & \\
\hline Ethr & roup & $\mathrm{C}$ & DR & PR & $\mathrm{C}$ & DR & PR & $\mathrm{C}$ & DR & PR \\
\hline & & STV* & & & STV* & & & STV* & & \\
\hline $\mathrm{AG}$ & 1 & 11.8 & 10.7 & 6.7 & 2.5 & 3 & 10 & -9.3 & -7.7 & +3.3 \\
\hline & 2 & 24.3 & 10 & 3 & 5.7 & 12.8 & 2.2 & -18.6 & +2.8 & -.8 \\
\hline & 3 & 42.3 & 8.7 & 25.3 & 0 & 15 & 0 & -42.3 & +6.3 & -25.3 \\
\hline $\mathrm{TG}$ & & 22.9 & 9.8 & 10.8 & 3.4 & 10.5 & 4.1 & -19.5 & +.7 & +.7 \\
\hline & & ETV* $^{*}$ & & & ETV* $^{*}$ & & & ETV* $^{*}$ & & \\
\hline $\mathrm{AG}$ & 1 & 24 & 15.7 & 22.7 & 14.5 & 18 & 21 & +9.5 & +2.3 & -2.7 \\
\hline & 2 & 12.5 & 10.8 & 22 & 21 & 27.3 & 30 & +8.5 & +16.5 & +8 \\
\hline & 3 & 12.5 & 4.3 & 12 & 20 & 21.3 & 22.5 & +7.5 & +17 & +10.5 \\
\hline $\mathrm{TG}$ & & 17.1 & 10.3 & 19.2 & 17.6 & 22.7 & 25.8 & +.5 & +12.4 & +6.6 \\
\hline
\end{tabular}

* Results are given in average of hours per week.

$C=$ Cubans; $D=$ Dominicans; $P R=$ Puerto Ricans

$S T V=$ Spanish TV; ETV = English TV

$A G=$ Age group: $1=20-35 ; 2=36-50 ; 3=51$ and over

$T G=$ Total group

Table 6 compares how often the subjects read Spanish- and Englishlanguage newspapers and magazines. The choices in the questionnaire constitute a continuum, they received numerical values, and an average was calculated. C, D, and PR from the FG read Spanish newspapers and magazines between "several times a week" and "once a week," with averages of 2.6, 2.9, and 2.9, respectively. There is variation, however, when it comes to reading English newspapers and 
magazines. PR read them with the same frequency (2.4 points), $\mathrm{C}$ read them between "once a week" and "several times a week" (3.5 points), and D read them between "several times a month" and "about once a month." Thus, FG PR are exposed to English-language written forms of communication more often than the FG members of the other ethnic groups. D are exposed to them less than the other groups.

Table 6. Comparison of first-and second-generation Cubans, Dominicans, and Puerto Ricans based on how often they read Spanish- and English-language newspapers and magazines

\begin{tabular}{|c|c|c|c|c|c|c|c|c|c|c|}
\hline \multirow{3}{*}{\multicolumn{2}{|c|}{\begin{tabular}{|l|} 
Generation \\
Ethnic group \\
\end{tabular}}} & & & & & & & \multicolumn{3}{|c|}{ Difference } \\
\hline & & \multicolumn{3}{|c|}{ First } & \multicolumn{3}{|c|}{ Second } & & & \\
\hline & & $\mathrm{C}$ & DR & PR & $\mathrm{C}$ & DR & PR & $\mathrm{C}$ & DR & PR \\
\hline & & \multicolumn{3}{|c|}{ SNM* } & \multicolumn{3}{|c|}{ SNM* } & \multicolumn{3}{|c|}{ SNM* } \\
\hline \multirow[t]{3}{*}{$\mathrm{AG}$} & 1 & 3.3 & 3.7 & 2.7 & 5.3 & 5.7 & 6.3 & +2 & +2 & +3.6 \\
\hline & 2 & 2.3 & 3 & 2.8 & 5.3 & 6 & 5.2 & +2 & +3 & +2.4 \\
\hline & 3 & 2 & 2 & 3.3 & 6 & 4 & 7 & +4 & +2 & +3.7 \\
\hline \multirow{2}{*}{\multicolumn{2}{|c|}{ TG }} & 2.6 & 2.9 & 2.9 & 5.4 & 5.3 & 5.9 & +2.8 & +2.4 & +3 \\
\hline & & \multicolumn{3}{|c|}{ ENM* } & \multicolumn{3}{|c|}{ ENM* } & \multicolumn{3}{|c|}{ ENM* } \\
\hline \multirow[t]{3}{*}{$\mathrm{AG}$} & 1 & 3 & 5 & 1.3 & 1.5 & 3.3 & 3.3 & -1.5 & -1.7 & +2 \\
\hline & 2 & 4.3 & 4 & 2.8 & 2 & 3.3 & 2.4 & -2.3 & -.7 & -.4 \\
\hline & 3 & 3 & 5 & 3 & 1 & 2.3 & 2 & -2 & -2.7 & -1 \\
\hline \multicolumn{2}{|l|}{$\mathrm{TG}$} & 3.5 & 4.6 & 2.4 & 1.6 & 3 & 2.6 & -1.9 & -1.6 & +.6 \\
\hline
\end{tabular}

$*$ Results are given in averages of points on the following scale: $1=$ Daily; $2=$ Several times a week; 3 = Once a week; $4=$ Several times a month; $5=$ About once a month; $6=$ Less than once a month; $7=$ Never.

$C=$ Cubans; $D=$ Dominicans; $P R=$ Puerto Ricans

SNM = Spanish newspapers and magazines; ENM = English newspapers and magazines

$A G=$ Age group: $1=20-35 ; 2=36-50 ; 3=51$ and over

$T G=$ Total group

C, D, and PR from the SG read Spanish newspapers and magazines between "about once a month" and "less than once a month." The averages were 5.4, 5.3, and 5.9, respectively. C read English newspapers and magazines between "daily" and "several times a week" (1.6 points), PR read them between "several times a week" and "once a week" (2.6 points), and D read them between "once a week" and "several times a month" (3 points). This means that SG C are exposed to English-language written forms of communication more than any other ethnic group from the $\mathrm{SG}$.

The analyses of variance yielded significant results for generation and Spanish-language newspapers and magazines $(\mathrm{p}<.0001)$; for English-language newspapers and magazines, and sex $(\mathrm{p}<.0068)$; and for English-language newspapers and magazines, and generation and sex $(\mathrm{p}<.0083)$. The first case needs no explanation. The second case seems to be the result of males reading newspapers and magazines in English more frequently than females. The last case

Encrucijada/Crossroads 1.1 (2003): 33-46 
may have been determined by females, specifically by the difference in reading frequency between FG and SG females.

The results obtained from the questions that explored language use in five domains are summarized in Table 7. The numbers included in this table correspond to the alternatives provided in the questionnaire. In the job environment, FG D and C averaged between "mostly Spanish," and "both Spanish and English," with 2.3 and 2.7 points, respectively. PR averaged 3 points ("both Spanish and English"). There is more variation among the SG subjects. PR averaged between "mostly Spanish," and "both Spanish and English" (2.8 points), D averaged between "both Spanish and English," and "mostly English" (3.5 points), and C averaged between "mostly English" and "English only" (4.5 points). The order of the ethnic groups is practically inverted from one generation to the other.

Table 7: Comparison of first and second generation Cubans, Dominicans, and Puerto Ricans based on the language(s) used in five domains

\begin{tabular}{|l|c|c|c|c|c|c|c|c|c|c|c|}
\hline \multicolumn{9}{|c|}{} & \multicolumn{3}{c|}{ Sifference } \\
\hline Generation & \multicolumn{3}{|c|}{ First } & \multicolumn{3}{c|}{} \\
\hline Ethnic Group & C & D & PR & C & D & PR & C & D & PR \\
\hline Domains: & 3 & 2.3 & 2.7 & 4.5 & 3.5 & 2.8 & +1.5 & +1.2 & +.1 \\
\hline Job Environment & 1.8 & 1.7 & 2.1 & 2.9 & 2.6 & 3.2 & +1.1 & +.9 & +1.1 \\
\hline With Family Members & 2.3 & 2.1 & 2.5 & 3.9 & 3.4 & 3.4 & +1.6 & +1.3 & +.9 \\
\hline With Close Friends & 1.5 & 1.5 & 2.4 & 2.8 & 2.3 & 2.9 & +1.3 & +.8 & +.5 \\
\hline $\begin{array}{l}\text { With Other Members of the } \\
\text { Same Ethnic Group }\end{array}$ & 1.7 & 1.8 & 2.2 & 2.3 & 2.6 & 2.5 & +.6 & +.8 & +.3 \\
\hline With Other Latinos & & & & & & & & +.3 \\
\hline
\end{tabular}

* Results are given in averages of points on the following scale: 1 = Spanish only; 2 = Mostly Spanish; 3 = Both Spanish and English; 4 = Mostly English; 5 = English only.

$C=$ Cubans; $D=$ Dominicans; $P R=$ Puerto Ricans

$T G=$ Total group

When speaking with family members, D and $\mathrm{C}$ averaged between "Spanish only" and "mostly Spanish" (1.7 points and 1.8 points, respectively). PR averaged between "mostly Spanish," and "both Spanish and English," with 2.1 points. SG D and C averaged between "mostly Spanish," and "both Spanish and English" (2.6 and 2.9, respectively), while PR averaged between "both Spanish and English," and "mostly English" (3.2 points).

All the FG members prefer to use between "mostly Spanish," and "both Spanish and English" to speak with close friends (D 2.1 points, C 2.3 points, and PR 2.5 points). D, PR, and C from the SG prefer between "both Spanish and English," and "mostly English" in this context (D and PR 3.4 points each, and C 3.9 points). 
When speaking with other members of the same ethnic community, $\mathrm{C}$ and D averaged between "Spanish only" and "mostly Spanish" (1.5 points each), whereas PR averaged between "mostly Spanish," and "both Spanish and English." All SG members also averaged between "mostly Spanish," and "both Spanish and English" (D 2.3 points, C 2.8 points, and PR 2.9 points).

Finally, when speaking to other Hispanics/Latinos, C and D prefer between "Spanish only" and "mostly Spanish" (1.7 points and 1.8 points, respectively), while PR prefer between "mostly Spanish," and "both Spanish and English" (2.2 points). This is also the preference of all the SG subjects: C with 2.3 points, PR with 2.5 points, and $\mathrm{D}$ with 2.6 points.

The generation an individual belongs to correlated significantly with the five domains: the job environment $(\mathrm{p}<.0007)$, interactions with family members $(\mathrm{p}<.0001)$, interactions with close friends $(\mathrm{p}<.0001)$, interactions with other members of the same ethnic community $(\mathrm{p}<.0002)$, and interactions with other Latinos ( $\mathrm{p}<.0264)$. The SG has clearly incorporated the English language more into their linguistic patterns in these five contexts. The job domain also correlated with generation and ethnic group ( $\mathrm{p}<.0162)$, which corroborates that the increase in English use in these contexts by the SG members applies regardless of ethnic group. Sex, and generation and sex did not prove to be significant in their interaction with the variables being considered.

\section{Discussion and Conclusions}

The results of this study point to several issues about the linguistic decision process that Latinos from a Cuban, Dominican, and Puerto Rican background living in the New York City metropolitan area go through:

1. Recent immigrants, evidently, grew up in a home were Spanish was the (exclusive) language of communication. Descendents of immigrants, on the other hand, also grew up in homes were Spanish was widely used, despite the unquestionable use of English. Both cohorts, nonetheless, currently live in homes where English is used more than what it was used in the homes where they grew up. A qualification is in place. FG members have already integrated the new linguistic code in the communication that takes place in this setting. If we compare the linguistic situation of the home settings in which members of the SG grew up, many predictions can be established. The SG of the future is being exposed to even more English at home. If the pattern verified in the current SG is that the use of English increases once they reach adulthood, then one can expect the SG of the future to continue integrating even more English. The home has been considered the domain that guarantees language maintenance, even the cause of the relative success that Latinos have had compared to other immigrant groups. Unfortunately, this may change several generations from now.

Encrucijada/Crossroads 1.1 (2003): 33-46 
2. The results regarding language(s) used at home confirmed what Ofelia García, Isabel Evangelista, Mabel Martínez, Carmen Disla, and Bonifacio Paulino reported on $\mathrm{C}, \mathrm{D}$, and $\mathrm{PR}$ in New York City. In this environment, D use more Spanish than C and PR. FG and SG D reported more use of Spanish in the home at age 13 and at the present time (496). At the same time, the results do not provide evidence that PR, the most represented Latino group in New York City, have maintained their mother tongue more than the other Latino groups.

3. In New York City, radio and television stations, music stores, and the press cater to the linguistic needs and preferences of Latinos. With more than four radio stations, more than two television stations, and access to many musical genres and publications in Spanish, Hispanics have many choices when it comes to media. These choices bring multiple results. Overall, the FG prefers Spanish means of communication compared to the SG, with a few exceptions. First, members of the FG and SG watch more English-language television than Spanish-language television. Younger $\mathrm{C}$ do not conform to this generalization. (The differences between the FG and SG, nevertheless, were significant.) Second, although the FG reads newspapers and magazines in Spanish with more frequency than in English, they evidently read more in English than what the SG reads in Spanish. They have already accommodated what is available in English into their reading habits. (The difference in the frequency with which subjects read in Spanish was significant for generation. The difference in English was not.) FG PR are the exception; they read more in English than in Spanish.

4. The linguistic skills that the FG has developed in English and that the SG has developed in Spanish reflect on the languages they use in different domains. This is important for, as Silva-Corvalán says, the more domains Spanish is used in, the more competence its speakers will have in the language (Algunos aspectos 236). Spanish is used-at various levels - on the job, with family members, with close friends, with other members of the same ethnic community, and with other Hispanics/Latinos, but English has clearly infiltrated in the job environment and in interactions with close friends, more so than in the other three domains. The SG steadily reported using more English than the FG in the five domains. (The differences among generations were significant.) Among the members of the latter group, PR reported higher values on the scale than $\mathrm{C}$ and $\mathrm{D}$ did. It is hard to say for the SG. C and PR reported higher values on the scales for two domains, respectively, whereas $\mathrm{D}$ reported higher values than $\mathrm{C}$ and $\mathrm{PR}$ in one domain. These findings are very important; they question the somewhat romantic idea that Latinos exemplify the possibility to maintain a mother tongue in a society in which English is the dominant language. This idea has been documented by scholars who study the status of Spanish in the U.S., however, it is imperative to conduct more studies in order to determine if there are new trends permeating linguistic choices made by Latinos. 
5. The results confirm what García et al. argue: among PR and C it is more common to use both Spanish and English with their parents, siblings, and children - family - than among D (494). C, D, and PR in the New York City not only see the value of Spanish but also employ it in domains that relate to their personal and developmental needs.

Encrucijada/Crossroads 1.1 (2003): 33-46 


\section{Notes}

1 Hudson County, NJ has the largest Cuban population in the New York City metropolitan area, with $24 \%$ of the Hispanic population. In West New York, one of the cities in this county, 45\% of all Hispanics are Cuban. (From the 1990 Census of Population: Social and Economic Characteristics-New Jersey.)

${ }^{2}$ This study was part of a much larger study that considered other issues not related to the focus of this paper.

${ }^{3}$ Since the answers provided in the questionnaire by the subjects were in hours per week, a six-point scale was created to perform the statistical analysis: $1=0-5$ hours per week; $2=6-10$ hours per week; $3=11$-15 hours per week; $4=16$-20 hours per week; $5=21$-25 hours per week; 6 $=25$ or more hours per week. 


\section{Works Cited}

Bean, Frank, and Morta Tienda. The Hispanic Population of the United States. New York: Russell Sage Foundation, 1987.

García, Ofelia, Isabel Evangelista, Mabel Martínez, Carmen Disla, and Bonifacio Paulino. "Spanish Language Use and Attitudes: A Study of Two New York City Communities." Language in Society 17 (1988): 475-511.

Portes, Alejandro and Richard Schauffler. "Language and the Second Generation: Bilingualism Yesterday and Today." International Migration Review 28 (1994): 640-61.

Silva-Corvalán, Carmen. "Algunos aspectos de la gramática de los niños bilingües de Los Angeles.” Bilingüismo y adquisición del español. Ed. H. Urrutia Cárdenas and Carmen Silva-Corvalán. Bilbao, Spain: Instituto Horizonte, SL, 1992. 227-39.

---. Language Contact and Change: Spanish in Los Angeles. Oxford: Clarendon, 1994.

Solé, Yolanda Russinovich. R. "Bilingualism: Stable or Transitional?: The Case of Spanish in the United States." International Journal of the Sociology of Language 84 (1990): 35-80.

United States. Department of Commerce. Bureau of the Census. Census of Population and Housing: Census Tracts and BNA's (New York). Sections I, II, III, and IV. Washington: GPO, 1990.

---. Census of Population: Social and Economic Characteristics (New Jersey). Volume I. Washington: GPO, 1990. 